\title{
AUTUMNBOOKS
}

\section{Peaks in climate research}

\section{Lonnie Thompson climbs every mountain to look for clues to climate change.}

Thin lce: Unlocking the Secrets of Climate in the World's Highest Mountains

by Mark Bowen

Henry Holt: 2005.480 pp. $\$ 30$

\section{Georg Hoffmann}

"The closest living thing to Indiana Jones, and just in time." That's how Harvard geochemist Daniel Schrag described Lonnie Thompson, the pioneer of high-altitude ice-core drilling of tropical and subtropical glaciers. Thompson has probably spent more time at altitudes of 6,000 metres and above than anyone else. But when he started his drilling campaigns in the 1970 s, in such remote places as the Quelccaya ice sheet in Peru, it was an adventure against long odds. Starting from his laboratory at Ohio State University, Thompson faced technical, practical and scientific problems considered by most of his colleagues to be unsolvable. More than thirty years later, the first summary of this most unusual career has appeared.

In Thin Ice, Mark Bowen, a physicist and passionate mountain-climber, describes the numerous expeditions that Thompson and his colleagues organized — from the Andean Altiplano to Tibetan ice sheets, from the Alaskan Bona-Churchill glacier to Mount Kilimanjaro in Kenya. Of the peaks capped with drillable amounts of ice, only a handful still await exploration by Thompson and his group.

It was widely believed that even if the researchers overcame the impossibility of retrieving an ice core from high altitudes, they would never be able to date, analyse and interpret the ice appropriately. In fact, they demonstrated that the entire concept was entirely feasible. When attempts to airlift heavy polar drills to high-altitude glaciers failed, they designed and constructed special lightweight drilling equipment that could be carried on foot. But these technical advances did not spare Thompson's team the discomforts of draughty, cold, low-oxygen conditions atop the glaciers, on which they spent months locating high-quality ice samples and battling with a range of technical problems.

Chemical and isotopic analyses of tropical ice cores showed convincingly that the tropics, far from being an immutable part of the global dimate system, were participating in the rapid cold and warm swings documented at higher latitudes. The publication of the results from Huascarán and Sajama, two Andean mountain

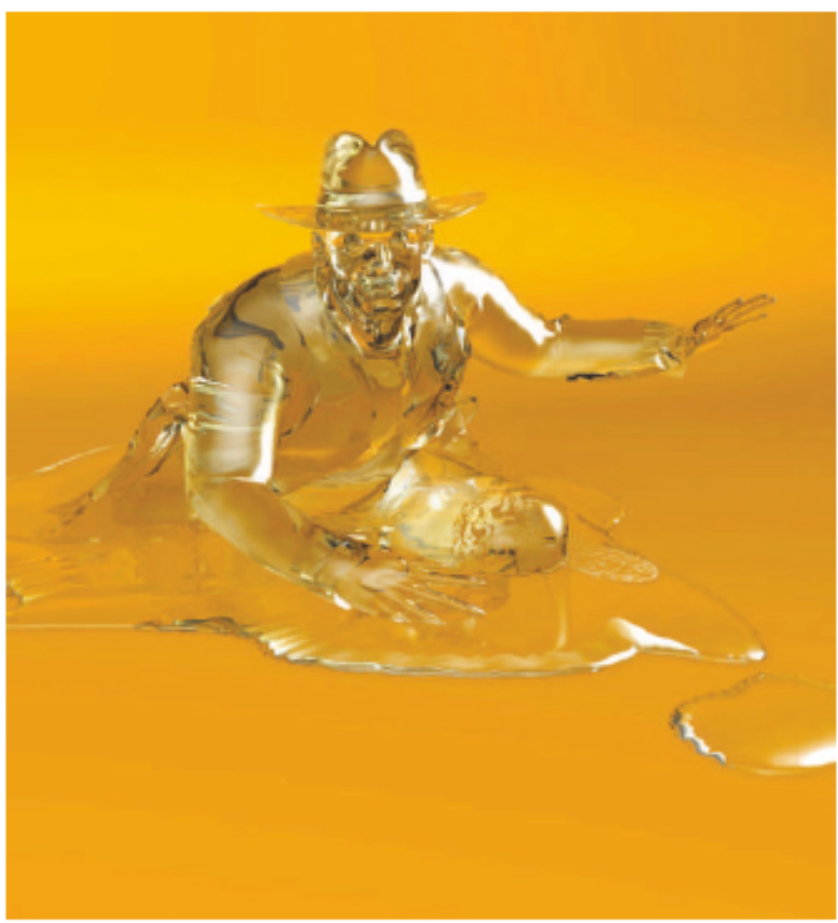

rewarding drilling sites the quality of many signals in the ice has already been degraded by recent warming. The Quelccaya ice sheet, for example, no longer experiences surface temperatures low enough to allow the preservation of a seasonal water isotope signal. Meltwater is now percolating down through the upper metres of compacted snow, affecting all proxy information buried in the ice. Quelccaya's glaciers have become hundreds of metres shorter since Thompson started his work thirty years ago.

We can only speculate on how the disappearing tropical glaciers and their water resources will affect those living in Peru and Bolivia in the near future,

giants that Thompson successfully drilled, changed many dimatologists' way of thinking. Bowen has adopted the still controversial idea that the tropics are a significant driver of rapid dimate variability, arguing against what he calls the North Atlantic school. But most palaeoclimatologists still belong to the latter camp, remaining convinced that the most potent regulator of the global climate system is hidden somewhere near Greenland at the turnover point of the ocean's thermohaline circulation. Even though I am personally not yet convinced by the arguments of the "tropical school', I found this vivid description of an ongoing scientific discussion to be one of the most compelling stories that Thin Ice has to tell.

Bowen adds a political dimension to the scientific narrative, arguing strongly for the promotion of climate change to the ranks of the world's most pressing problems. The assertion is justified by the race against time for researchers such as Thompson who are trying to extract information about past and present climate shifts from the world's disappearing glaciers. Had Thompson started his work today, many of the frozen archives he used would not have been considered as potentially but we have some good guesses about what regional climate swings meant to the people living on the Altiplano in the past. Thompson's work has been enthusiastically embraced by archaeologists, particularly those interested in the rise and fall of various pre-Incan societies. Sequences of favourable wet periods and adverse dry periods were accurately archived in Quelccaya's ice, and provide a convincing explanation for the evolution of ancient civilizations of the New World.

Bowen, who accompanied Thompson on two of his expeditions, tells this story in an amusing and entertaining style. The book often changes its focus, switching from thrilling mountaineering anecdotes to interviews with different scientists and historical retrospectives of Earth science. Often Bowen delivers fine pieces of science journalism, describing for example Charles Keeling's first measurements of carbon dioxide in the $1950 \mathrm{~s}$ on Mauna Loa, Hawaii. Thin Ice is at the same time a scientific biography, a fine introduction to the sciences of climate change, and a vivid description of a geophysicist's work under most extreme conditions.

Georg Hoffmann is at LSCE/CEA, Orme des

Merisiers, Gif sur Yvette 91191, France. 